\title{
Sir Robert Hutchison's Petition and the Medical Humanities
}

\author{
'From inability to let well alone \\ From too much zeal for the new and contempt for what is old \\ From putting knowledge before wisdom, science before art, and \\ Cleverness before common sense; \\ From treating patients as cases; \\ And from making the cure of the disease more grievous than the \\ Endurance of the same, Good Lord, deliver us.' - Sir Robert Hutchison
}

Sir Robert Hutchison was physician to the London Hospital and to the Hospital for Sick children at Great Ormond Street in the later part of the nineteenth and early part of the twentieth century. $\mathrm{He}$ is famous for his book 'Clinical Method', first published in 1897. The twenty-second edition of this path-breaking book on clinical examination has recently been published. Sir Robert Hutchison is famous for his clinical sayings and especially for his petition written in his later years. In this article I examine Hutchison's petition with reference to Medical Education in general and Medical Humanities education in particular.

I am a Clinical Pharmacologist and a medical educator at KIST Medical College, Lalitpur, Nepal. I am especially interested in the Medical Humanities (MH). In a blog article I had described how I started a $\mathrm{MH}$ module for students at two medical schools in Nepal and conducted a module for faculty members with the help of a fellowship offered by FAIMER (Foundation for Advancement of International Medical Education and Research). ${ }^{1}$ The $\mathrm{MH}$ module for first year undergraduate medical (MBBS) students was called Sparshanam meaning 'touch' in Sanskrit, an ancient language from which many languages of South Asia are derived. The module facilitators had in a recent article described their experiences with designing and conducting the $\mathrm{MH}$ module. ${ }^{2}$ The module used paintings, group activities, role plays and occasional literature excerpts to examine various aspects of the humanities. Hutchison's petition was discussed in detail by the student groups during the module with comments by the facilitators.

\section{Inability to let well alone}

The petition starts with the statement 'from inability to let well alone'. In the modern world drugs are increasingly being promoted and used for improving normal functioning and for conditions which can be regarded as physiological and a part of normal life. Convincing healthy people they are sick or can use medicines to further improve their functioning will enormously increase the market for medicines. Medicalisation has been described as the process of turning ordinary life events and the ups and downs of normal life into medical conditions. The phenomenon of disease mongering has attracted attention recently. Disease mongering can turn ordinary ailments into medical problems, see mild symptoms as serious, treat personal problems as medical ones, see risk factors as diseases and frame prevalence estimates to increase the market for medicines. ${ }^{3,4}$ Knowing when to prescribe a medicine and when not to prescribe medicines is an important skill for a doctor. Using drugs for physiological conditions may not be a good option. Many conditions respond to non-drug measures and psychological counseling and support. Life style diseases are becoming more common and maintaining a healthy life style can reduce the prevalence of these diseases.

\section{Zeal for the new and contempt for the old}

In the second line Sir Robert Hutchison talks about too much zeal for what is new and contempt for what is old. I will first examine this statement in the context of modern drugs and then look at it in the context of other treatment modalities. Newer drugs are strongly promoted and marketed for a number of conditions. In many cases a new drug may not be the best treatment option available. Drugs are tested on animals and then undergo clinical trials on healthy volunteers and patients before they are marketed. The problem is that these studies are carried out on a limited number of patients only. Many conditions of normal use of the drug are not addressed in clinical trials. Considering the limitations of data obtained from clinical trials even after a drug is marketed it remains under postmarketing surveillance. Many adverse effects become evident only after marketing and widespread use of a drug.

The famous clinical pharmacology textbook by Bennet and Brown has a diagram describing the life cycle of a drug. ${ }^{5}$ A drug is usually introduced with much hype in the market. Initially people are skeptical but then the drug shows good results in early studies. The drug is then hyped as a "wonder drug". Soon, however, reports of serious adverse effects are noted, and sometimes even deaths occur. The drug is then at the nadir of its popularity. People begin to term the drug 
as a poison. Eventually we know more about the drug and begin to understand it better. We know in which conditions it can be used and what are the precautions regarding its use. Eventually the drug finds its status in therapeutics. This may also be true of many new non-drug treatment modalities. Old and trusted treatments which have been used for many years in a variety of patients are worth their weight in gold.

\section{Knowledge before wisdom, science before art}

The third line talks about the hazards of putting knowledge before wisdom and science before art. In the early seventies and eighties in developed nations concern was raised about the overemphasis on science in modern medicine. Modern medicine has developed on scientific discoveries but the neglect of the art of healing had led to many deleterious consequences. $\mathrm{MH}$ arose as a result of acknowledgement of these deficiencies and aims to provide the contrasting perspective of the arts to the scientific one which dominates modern medicine. The practice of medicine is both a science and an art and we neglect the art at our peril. Today $\mathrm{MH}$ programs are well established in developed nations and have been started in certain developing nations also.

Wisdom is defined as understanding the limits of one's knowledge and skill. It has been said that person with knowledge is proud that he/she knows so much while a person who also has wisdom is apologetic that there is so much more to know. Knowing the limits of one's knowledge and where he/she or the patient can obtain more information is important in modern medical practice. Many eminent personalities in medicine including Sir William Osler, the father of modern medicine have repeatedly emphasized the importance of 'wisdom'.

\section{Treating patients as cases}

In the scientific and technical context of modern medicine it is easy to forget about the patient as a human being and about the human dimensions of suffering. In a busy teaching hospital patients are liable to be considered as cases. At KIST Medical College we discourage patients being referred to as cases and encourage students to approach them as human beings. Illness causes a number of changes in the life of an individual. When a sick person enters a hospital, all that is familiar is left behind. ${ }^{6}$

$\mathrm{MH}$ teaches students to treat patients as human beings. It employs initiatives such as sessions on the doctor-patient relationship, looking at the human dimensions of illness, obtaining a holistic narrative history of patients, and 'parallel charting'. ${ }^{7,8,9}$ In parallel charting in addition to the usual formal case history an additional history is obtained dealing with the effect of the illness on the persons' life, his/her family and community. Many years before $\mathrm{MH}$ terminology came into vogue, the astute Doctor Hutchison recognized the importance of treating patients as humans and not as hospital numbers or cases with an interesting disease.

\section{Making the cure of the disease more grievous than the} endurance of the same

Drugs and modern technological procedures can relieve symptoms, prevent disease, offer palliation and pain relief, and occasionally cure. The issue of quality of life, euthanasia and helping patients to die with dignity is hotly debated. In our $\mathrm{MH}$ sessions euthanasia and the right to die with dignity is discussed in detail by faculty and students. Some patients with no real hope of a cure are often aggressively treated with medicines and radiation; procedures and medicines that are expensive and can be a huge drain on family finances (especially in developing countries). Cancer patients so treated may suffer from nausea and vomiting, ulceration of mucous membranes, loss of hair, decreased immunity, and increased risk of infection.

One of my students who worked in a remote district after graduation recently came to visit me saying that in many cases of terminal cancer he advocates only symptom relief and advises patients and their families not to pursue aggressive and expensive modern medical treatment. I think this is a sensible policy elsewhere as often families exhaust all their resources treating 'incurable' patients. The issue of what is 'incurable' however, is often difficult to determine. Lack of resources and finances makes life difficult for the living relatives.

\section{Good lord deliver us}

Asking God to save us or protect us from evil is a common practice while praying to the Lord not only in Hutchinson's Christianity but also in other religions. When we used the petition in our $\mathrm{MH}$ classes certain students (of other religions) had difficulty in understanding these words and so failed to properly interpret Hutchison's petition. We as facilitators had to tell them about Hutchison telling students and doctors to avoid various actions and practice medicine in a humane and compassionate manner. On pointing out the modification they were able to follow the thoughts of the writer and understand the importance of Sir Robert Hutchison's message.

Sir Robert Hutchison's petition, written more than 75 years ago in an environment of medical practice quite different from what we are accustomed to, remains still relevant today.

\section{Acknowledgement}

The author would like to acknowledge the help of Dr. Donald Messerschmidt, Anthropologist and creative writer, Vancouver, Washington, United States in copyediting the manuscript and suggesting modifications. 


\section{References}

1. Shankar PR. Establishing Medical Humanities in Nepal with the help of a FAIMER fellowship. 2010 [cited Accessed on February 12, 2010]; Available from: http://blogs.bmj.com/medicalhumanities/2009/12/07/establ ishing-a-medical-humanities-in-nepal-with-the-help-of-afaimer-fellowship-by-ravi-shankar.

2. Shankar PR, Piryani RM, Thapa TP, Karki BMS. Our experiences with 'Sparshanam', a medical humanities module for medical students at KSIT Medical College, Nepal. J Clin Diag Res. 2010;3:2158-62.

3. Shankar PR, Subish P. Disease mongering. Singapore Med J. 2007;48:275-80.

4. Moynihan R, Heath I, Henry D. Selling sickness: the pharmaceutical industry and disease mongering. BMJ. 2002;324:886-90.
5. Bennett P, Brown M. Clinical pharmacology. Edinburgh: Churchill Livingstone Tenth edition; 2008. p.60.

6. Aull F. Ten Years of Medicine and the Arts In: Dittrich L, editor. Patient' stories Washington, D.C.: Association of American Medical Colleges; 2001. p.33.

7. DasGupta S. Between stillness and story: lessons of children's illness narrative. Pediatrics. 2007;119:e1384-91.

8. Kidd M, Connor J. Striving to do good things: Teaching humanities in Canadian medical schools. J Med Humanit. 2008;29:45-54.

9. Kumagai A. A conceptual framework for the use of illness narratives in medical education. Acad Med. 2008;83:653-8.

P. Ravi Shankar, M.D.

KIST Medical College Lalitpur, Nepal

Email: ravi.dr.shankar@gmail.com 